\title{
El Peregrino que beeq..o
}

\section{CALOR DE HOGAR O CALOR DE "INFIERNO"}

\author{
Padre Gabriel Sáenz ${ }^{+1+}$
}

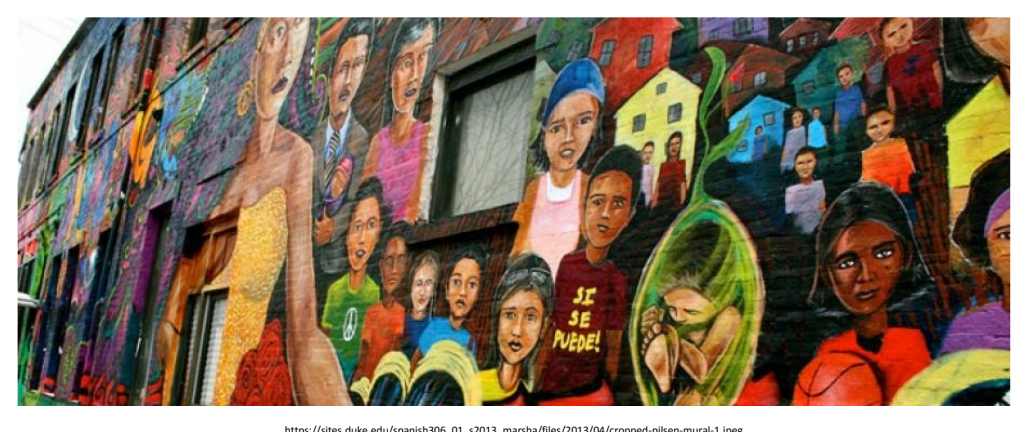

A principio de este año, el papa Francisco dio a conocer la exhortación apostólica postsinodal titulada Amoris Laetitia, sobre el amor en la familia (Francisco, 2016). Confieso que mi primer impulso fue escribir algunas reflexiones relacionadas con el amor, pero este proyecto se me derrumbó al leer el editorial del diario El Tiempo (7 de agosto de 2016) titulado "Hogares que son infierno" (en Colombia), por lo cual me decidí a reflexionar sobre el segundo capítulo de la antedicha exhortación papal relacionada con la crisis familiar en el mundo.

\section{Comenta el editorial:}

"No solo horror, produce escalofrío y desolación conocer que son tantos los hogares colombianos epicentro de agresiones físicas y sexuales, muchas de ellas contra niños, adolescentes y adultos mayores... estas cifras de agresión pasaron del $86 \%$ en 2014 al $88 \%$ en 2015. La vivienda ocupa el primer lugar en la lista de sitios donde estas ocurren, así como los homicidios... en el 32,88 \% de los casos fue el padre, en el 30,69 \% la madre y en el $42,36 \%$ un familiar... uno de cada tres asesinatos en Colombia tiene lugar en el marco de una celebración... el calor de hogar se convierte en calor de infierno". (El Tiempo, 2016, p. 14). Hasta aquí lo que comenta este diario.

Pienso que uno de los factores que más debilitan la relación familiar es el hecho de no saber reconocer o aceptar los errores del otro, en otras palabras, la intolerancia. El hombre es un ser nómada que va con sus propios errores en busca del "otro" que lo acoja como es, sin avergonzarse de lo que es. No avergonzarse de mostrar sus errores, no aceptar al "otro" tal como es, produce automáticamente la infidelidad y posteriormente la promiscuidad, lo que da origen a las tragedias pasionales casi siempre en el marco de una celebración sustentadas por el alcohol o la droga.

Comenta el Papa Francisco en su exhortación: "Se cree que el amor, como en las redes sociales, se puede conectar o desconectar a gusto del consumidor e incluso bloquear rápidamente... todo es

$\$+$ Capellán CJNC. Consejero Pastoral FUJNC. 
descartable, cada uno usa y tira, gasta y rompe, aprovecha y estruja mientras sirva. Después iadiós!" (Francisco, 2016, p. 31).

Así, pues, vamos en contra de la razón natural, amamos las cosas y usamos a las personas en vez de hacer todo lo contrario y cuando alguien ya no "nos sirve" lo botamos al basurero de la vida. Lo ideal es pensar que no es la condena o el juicio lo que puede rescatar al "otro" sino un amor acogedor que abrace. iEl amor acogedor es obviamente el perdón! Sin embargo, hay ocasiones en que estamos tan heridos, tan traicionados y humillados que es casi imposible el perdón, humanamente hablando.

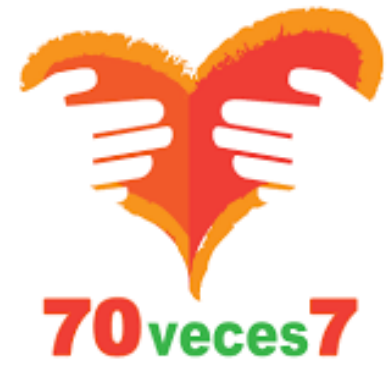

Se debe tener en cuenta que el perdón es una decisión de la voluntad, una experiencia difícil, una actitud y un proceso que no es puntual sino que puede tomar años $y$, en ocasiones, hasta la muerte.

Una de los más valientes y ejemplarizantes casos de perdón a finales del siglo XX fue el de Inmaculé Ilibagiza, la ruandesa que perdió a toda su familia durante el genocidio en su país, Ruanda, hace un poco más de veinte años. Se salvó tras permanecer escondida por 90 días en un baño de un metro por un metro. Hoy recorre el mundo hablando del perdón. Vive en Nueva York, está casada y tiene dos hijos y relata su historia en el libro Sobrevivir para contarlo (Ilibagiza, 2006).

Francisco (2016) comenta: "Las crisis matrimoniales frecuentemente se afrontan de un modo superficial y sin la valentía de la paciencia, del diálogo sincero, del perdón recíproco, de la reconciliación y también del sacrificio" (p. 44).

Otros de los factores que produce violencia familiar son el alcohol y la drogadicción tanto en adultos como en adolescentes. Cuando hay rencores y rabias escondidas en el corazón, el alcohol y la droga destapan la "olla a presión" y la celebración; como dice El Tiempo (8 de agosto de 2016), acaba en tragedia. Dice el papa Francisco (2016) "la droga-dependencia es una de las plagas de nuestra época que hace sufrir a muchas familias y no pocas veces termina destruyéndolas" (p. 213). Existen otros temas como el maltrato y abuso sexual en la mujer, el feminicidio, la cultura del hedonismo que darían para futuras reflexiones.

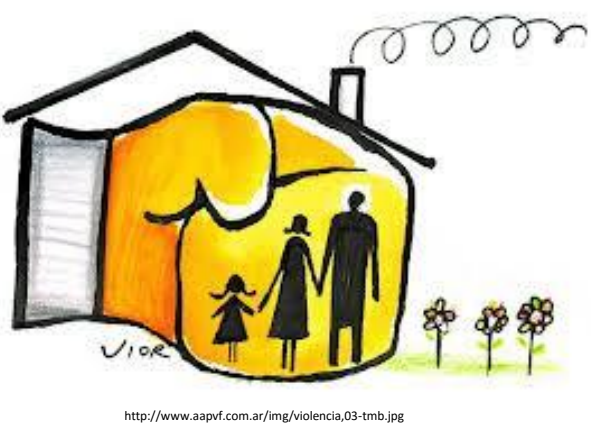

Finalmente, no podríamos cerrar estos comentarios sin referirnos a la dolorosa pero real situación de maltrato por parte de la sociedad y su propia familia hacia el adulto mayor. Francisco (2016) se refiere a este tema citando el Salmo 70(71):

"No me rechaces ahora en la vejez, me van faltando las fuerzas, no me abandones... es el clamor del anciano que tiene el olvido y el desprecio... los ancianos son hombres y mujeres que estuvieron antes que nosotros, en nuestra misma casa, en nuestra diaria batalla por una vida digna..." (Francisco, 2016, p. 148).

En la edición No 128 (sep.-oct.), de la Carta Comunitaria, se reflexionó ampliamente sobre este tema. Decíamos que, excepto cuando nos toca vivirlo en forma personal o familiar, es poco el tiempo que le dedicamos a reflexionar acerca de quienes nos han abierto el camino, nos han dado la vida, quienes construyeron el país o están por terminar la vida, es decir, los ancianos. 
Hace aproximadamente 50 años, el sacerdote brasileño José Fernández de Oliveira, compositor de música religiosa, más conocido como el padre Zezinho, compuso un hermoso himno a la familia conocido con este nombre. Algunas de sus estrofas rezan así:

Que ninguna familia comience en cualquier de repente. Que ninguna familia se acabe por falta de amor.

La pareja sea el uno en el otro de cuerpo y de mente, y que nada en el mundo separe un hogar soñador. Que ninguna familia se albergue debajo del puente y que nadie interfiera en la vida y en la paz de los dos, y que nadie los haga vivir sin ningún horizonte, y que puedan vivir sin temer lo que venga después. La familia comience sabiendo por qué y adónde va. Y que el hombre retrate la gracia de ser un papá. La mujer sea cielo y ternura y afecto y calor. Y los hijos conozcan la fuerza que tiene el amor. Que marido y mujer tengan fuerza de amar sin medida Y que nadie se vaya a dormir sin buscar el perdón.

Fernández de Oliveira, (s. f.)

Cerremos esta cruda pero real reflexión con un toque de fe, esperanza y amor invocando la presencia de la Sagrada Familia de Nazaret en nuestros hogares. Tomemos la oración con la que el papa Francisco cierra su exhortación apostólica Amoris Laetitia:

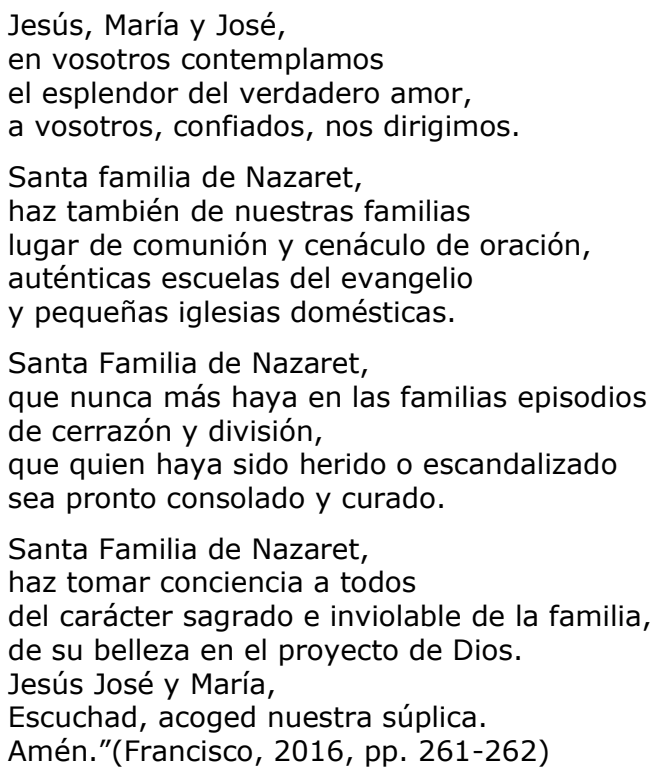

\section{Bibliografía}

Casa Editorial El Tiempo. (8 de Agosto de 2016). Hogares que son infiernos. El Tiempo, pág. 14.

Francisco. (2016). Exhortación apostólica postsinodal. Bogotá, D.C.: Instituto Misionero Hijas de San Pablo.

Immaculée Ilibagiza, S. E. (2006). Sobrevivir para contarlo: cómo descubrí a Dios en medio del holocausto en Ruanda. California: Hay House. 